\title{
Promoting the Human Rights of Children With Neurologic Conditions
}

\author{
Keiko Shikako-Thomas, PhD, OT,", and Meaghan Shevell, MA (Human Rights)
}

\begin{abstract}
Children with neurologic conditions benefit from international conventions, and national treaties, policies and regulations that safeguard their human rights. These regulations also exist to serve as guidance in the creation of comprehensive systems of care, inclusive environments, accessible societies and communities that allow these children to thrive and to achieve the best of their capacities. This narrative review of issues related to human rights and advocacy in pediatric neurologic disabilities will provide an overview of the human rights conventions that relate to children with disabilities, and the most current approaches implicating health care providers in rights promotion for these individuals and their families. We also suggest venues for professionals to advocate for their patients, and suggest strategies to consider rights-based approaches as a mean to provide holistic care in a social neurology framework.
\end{abstract}

Semin Pediatr Neurol 27:53-61 @ 2018 Elsevier Inc. All rights reserved.

\section{Introduction}

Children with neurologic conditions are children first, and as such they benefit from international conventions, and national treaties, policies and regulations that have been developed to support their optimal development and ultimately safeguard their human rights. These regulations also exist to serve as guidance in the creation of comprehensive systems of care, inclusive environments, accessible societies and communities that allow these children to thrive and to achieve the best of their intrinsic capacities. ${ }^{1-3}$ Nevertheless, children with neurologic conditions and their families are often unable to realize basic rights such as access to adequate health and education, including having access to information on the rights they are entitled to. Furthermore, this vulnerable group falls in an intersectional gap between the rights of children, ${ }^{4}$ the rights of persons with disabilities, ${ }^{5}$ and the essence of basic human rights for all. ${ }^{6,7}$

Service providers, including child neurologists and other health care professionals, are responsible for providing care for

From the *Participation and Knowledge Translation in Childhood Disability Lab, School of Physical and Occupational Therapy, McGill University, Montreal, QC, Canada.

'Department of Pediatrics, Montreal Children's Hospital, Centre for Interdisciplinary Research in Rehablitation (CRIR), Montreal, QC, Canada.

Address reprint requests to Keiko Shikako-Thomas, PhD, OT, Schoolof Physical and Occupational Therapy, McGill University, 3654, Prom SirWilliam-Osler (D30), Montreal, QC, Canada H3GlY5. E-mail: keiko. thomas@mcgill.ca children with neurologic conditions. However, it is also their responsibility to foster the notion of rights, and to ascertain that services and care structures respect and promote these rights, ultimately contributing to child well-being and community development. This narrative review of issues related to human rights and advocacy in pediatric neurologic disabilities will provide an overview of the rights of children with disabilities, and the most current approaches implicating health care providers in rights promotion for these individuals and their families. We will also suggest venues for professionals to advocate for their patients, and suggest strategies to consider rights-based approaches as a mean to provide holistic care in a social neurology framework.

\section{Human Rights}

The UN Office of the High Commissioner for Human Rights (OHCHR) defines human rights as inherent to all human beings, regardless of class, nationality, sex, ethnicity, religion, or any other status. By virtue of being a member of the human race alone, all human beings are equally entitled to human rights protections without discrimination. ${ }^{8}$ Human rights are intended to encourage the core principles of equality, nondiscrimination, participation and inclusion, and establish normative standards that are (A) universal or available to all in their application; (B) inalienable, such that they are inherent at birth and cannot be removed, revoked or taken away; (C) indivisible with all rights achieving the same equal status of 
importance and necessity, and cannot be ranked hierarchically; and (D) interdependent and interrelated, with the fulfillment of one right linked to the realization of other rights. ${ }^{9}$ For example, the right to health depends on the realization of the right to access information regarding existing services, treatments, and support. Similarly, the right to education may depend on the fulfillment of the right to health, as a child may not be able to attend school due to an unmanaged chronic illness, or to the lack of adequate educational supports.

There are several human rights treaties, with the International Bill of Human Rights as their foundation. ${ }^{10}$ Collectively, human treaties and conventions constitute the corpus of international human rights law. Different treaties have been established over the years to reflect the particular needs of different vulnerable populations who experience added barriers in realizing basic human rights, including the following groups: women, children, racial minorities, migrants, and individuals with disabilities. These further elaborated conventions do not create "new rights," but rather reiterate and further clarify the same basic human rights with further details and structure $^{11}$ to account for the specific needs and context of these groups.

Signing or ratifying international human rights treaties places a legal obligation on the signing country (ie, State party) to respect and refrain from interfering in the fulfillment of human rights, to protect citizens from human rights abuses, and to take positive action or investment to facilitate the fulfillment of rights. State parties are also bound to submit reports to the UN at regular intervals, outlining progress and efforts made in implementing human rights (such as the creation of policies or legislative efforts), as well as specific measures undertaken to address current gaps and possible barriers in implementation.

\section{Children's Rights}

Children represent $27 \%$ of the world's population, ${ }^{12}$ and as such the conditions that they live in and the systems put in place to ensure their full development are accorded significant global importance. This worldwide commitment and international support is evidenced by the ratification of the UN Convention on the Rights of the Child (CRC), which is the most widely and quickly ratified human rights treaty in history, with all but one State (ie, the United States of America) ratifying the Convention. The CRC is comprised of 54 articles, covering a broad range of fundamental social, cultural, economic, civil and political rights of children, and is underpinned by the following 4 guiding principles: nondiscrimination, best interests of the child, survival and development, and the right to be heard.

The CRC is a ground breaking instrument of norm-creation, demonstrating international consensus regarding children as human beings with entitlements; this represents a radical shift in orientation of children to being subjects of rights, rather than mere objects of protection. ${ }^{13}$ The Convention seeks to achieve a delicate balance between protection and self-determination, encouraging both support from adult caregivers and the active participation of youth. ${ }^{14-16}$ The participation of children in decision-making in all matters that affect them is emphasized both as a guiding principle as well as a specific article (ie, Article 12) in the CRC, effectively applying pressure on governments to effect, implement and enforce domestic legislation that supports children's participation.

The CRC can serve as a valuable tool in advocating for children's rights and generating greater use of a human rights paradigm in public policy and advocacy. ${ }^{17}$ This is evidenced by a UNICEF study on the CRC and domestic legislation, which found that $66 \%$ of State Parties had incorporated the $\mathrm{CRC}$ into national law with court decisions citing the $\mathrm{CRC}$ and the rights enshrined, and 33\% incorporating various aspects of the Convention into their national constitution. ${ }^{18}$ However, the convention alone does not guarantee that rights will be respected, but rather it requires service providers and civil society to take action in monitoring, supporting, and advocating for implementation and maintenance.

The CRC explicitly engages nongovernmental groups and civil society in reporting on implementation efforts on the ground, supporting advocacy and the involvement of different stakeholders in monitoring and promoting the rights of children. ${ }^{19,20}$ The Convention can also be an important instrument for health care providers and professionals working with children at the grassroots level to better understand and frame their actions under a holistic view of rights-respecting health services. ${ }^{21,22}$

\section{Disability Rights}

As one of the latest human rights instruments, the Convention on the Rights of Persons with Disabilities (CRPD) was adopted in $2006^{23}$ and considers the specific rights experiences of persons with disabilities. ${ }^{24,25}$ With equality and nondiscrimination as central directives, it ensures that persons with disabilities enjoy human rights on an equal basis as other human beings. As for most human rights conventions, one of the overarching goals of both the CRPD and the CRC is to create a "code of implementation" that guides State Parties on how to enact policies, laws and administrative measures that support and secure human rights, and conversely how to abolish discriminatory regulations and practices that violate their rights. ${ }^{26}$

The CRPD purposely avoids adopting a rigid delineated definition of "disability," and instead emphasizes that the term is an "evolving concept" that is a result of an interaction between the individual's disability or impairment and the obstacles encountered in the context in which they live (eg, physical, social, cultural, and financial barriers) that hinder their full participation in society and the full enjoyment of their human rights. As such, the CRPD encourages an approach that address these environmental barriers in society through domestic legislation and social change.

As the first human rights convention to involve a range of grassroots advocacy groups in its drafting, the CRPD is an important catalyst in social change. The Convention continues to promote greater awareness of the capabilities of persons with disabilities, fighting against negative attitudes, prejudices, and stereotypes that undermine and discriminate against the full 
enjoyment of human rights by this population. ${ }^{27}$ Similarly to how the CRC challenged previous assumptions of children as objects rather than subjects of rights and protections, the CRPD challenged the prevailing assumption of persons with disabilities as incapable and dependent agents, requiring an approach characterized by charity and sympathy. ${ }^{28}$ Instead, the CRPD reinforces the notions of individual autonomy, agency, and advocacy for persons with disabilities.

The CRPD takes intra-group distinctions (eg, age, gender, and class) into consideration, recognizing the heterogeneity within the population of persons with disabilities and highlighting the intersectional discrimination experienced by "minorities within minorities," such as children, women, indigenous populations. Similarly, the CRC also recognizes children with disabilities as a population who require special consideration. Nevertheless, in practice, children with disabilities are often overlooked in the implementation and enactment of these conventions. As a result, children with disabilities frequently fall in a gap between services and systems offered for individuals with disabilities and concurrently those offered for children. $^{29}$

\section{Rights and Health Frameworks}

The change in the conceptualization of children with disabilities from objects of protection to subjects of rights is paralleled by a shift from the "medical model of disability" to the "social model of disability." The former emphasizes disabilities as a condition, focusing on the impairments caused by an underlying disease, whereas "the social model of disability" emphasizes that it is the barriers in society that are in fact disabling, not the impairments caused by the underlying medical condition itself. The social model of disability also attests that societal structures can be adapted to accommodate, or be universally accessible to, all individuals regardless of impairments. The social model of disability as a framework also creates the concrete possibility for health care providers in different fields to think and act beyond the scope of "healing" or "fixing" impairments, and to take on the responsibility of creating universally accessible environments or adapting existing services, structures, and communities. ${ }^{30}$

Similarly, the Social Determinants of Health framework and the World Health Organization's International Classification of Functioning, Disability and Health (ICF) promote a comprehensive understanding of health as a right. Both frameworks provide perspectives of how environmental conditions, such as where people live, their socioeconomic status, and the resources and services offered in that context can effect and determine their health, disability, or health condition. ${ }^{31,32}$ In this context, it is understood that health care providers have the ultimate responsibility to better understand these social contexts and factors affecting their patient's health. Health care providers are also uniquely positioned to use context-based information to more accurately develop strategies that directly target existing societal barriers. For instance, health care providers can understand the socioeconomic condition of their patients, and refer them to the adequate social supports and benefits they might be entitled for according to their needs, or create and advocate for services such as leisure activities, community care, home visits, and family respite care that can alleviate the deleterious effects of those social determinants on health outcomes. Ultimately, these efforts can better promote the health and well-being of their patients by supporting the reduction of inequalities and ensuring the consolidation of their human rights.

\section{A Rights-Based Approach to Health Service Delivery: The Right to Health}

The right to health is indispensable in the realization of other human rights, and is enshrined in several human rights instruments, including the Universal Declaration of Human Rights (UDHR) ${ }^{33}$ and the International Covenant on Economic, Social, and Cultural Rights (ICESCR). ${ }^{34}$ As part of the International Bill of Human Rights, the UDHR's inclusion of health as part of the right to an adequate standard of living ${ }^{35}$ is a ground breaking achievement, and served as a foundation for specific elaboration in future human rights conventions. The Right to Health is its own stipulated right ${ }^{36}$ in the ICESCR, recognizing both mental and physical health as essential components. The ICESCR legally imposes a contractual obligation on States that have ratified it to promote health with maximum effort within existing available resources. The right to health is also recognized in other human rights treaties, such as the CRC (Article 24) and the CRPD (Article 25), among others. ${ }^{37}$ Other declarations and documents such as the UN Millennium Development Goals (MDGs), and more recently the Sustainable Development Goals (SDGs) have also emphasized the right to health as critical in achieving social and human development. ${ }^{38,39}$

The World Health Organization defines "health" as "a state of complete physical, mental and social well-being, and not merely the absence of disease or infirmity." ${ }^{40}$ Promoting health, and not only curing diseases or addressing "conditions" is the mandate of every health care practitioner. A rights-based approach to health includes not only the provision of adequate care, but also that the underlying determinants of health be addressed. ${ }^{41,42}$ Essential characteristics of a rights-based approach to health include: access to quality services (including accessibility of built environments where health care is provided, and to institutions that can promote health such as community centers and others), high quality of care, universal access regardless of socioeconomic status or disability, and accountability in service provision. ${ }^{43,44}$

State parties are required to ensure that health-related goods, services, programmes, and facilities are made sufficiently and publicly available. ${ }^{45}$ These health goods and services must be accessible to everyone, including being within safe physical proximity for all segments of the population. Once more, particular attention must be given to groups that are subject of multiple discrimination, such as children, women, indigenous populations, and those living in rural areas. Additionally, these services must be made affordable for all including socially 
disadvantaged groups, based on the principle of equity. ${ }^{46}$ The right to health also encompasses the right to seek, receive and impart information on health-related issues. ${ }^{47}$ All health goods, services, and facilities must be acceptable, both for being culturally appropriate ${ }^{48}$ and respectful of medical ethics. These goods and services must be of a certain caliber of quality, meeting cultural, medical, and scientific standards.

As a fundamental principle of all human rights generally, nondiscrimination is critical in ensuring that health goods and services are provided on an equal basis, without distinction or exclusion based on any grounds, including disability, health status, or age. This demands specific attention to children, who are often living under structural and systemic inequalities. ${ }^{49}$ Children with disabilities living in low socioeconomic status, foster care, rural areas, or aboriginal origin, and others may be at additional risk of discrimination as services and systems often are not in place. ${ }^{50}$ It is imperative that health standards are specifically developed for these groups, and that protective measures are put in place to prevent health-related discrimination and violations of rights. Health care practitioners', administrators', and decision-makers' attitudes are fundamental to accomplish the aforementioned obligations of respecting, protecting, and fulfilling the right to health of children with neurologic conditions and their families.

All health and rights frameworks point to the factors in the environment where children live as having a direct influence on their health. In fact, children with disabilities are at risk for lower participation and other key developmental and health outcomes. ${ }^{51,52}$ Children living in lower socioeconomic settings are also at risk for worse health outcomes of different natures, such as asthma and other chronic conditions. ${ }^{53}$ Other factors such as caretaker mental health, community violence, and the surrounding built environment have been associated with a series of adverse health outcomes. ${ }^{54,55}$ Additionally, children with disabilities are particularly at risk for being exposed to heavy financial constraints on families; ${ }^{56-59}$ caretakers burden, including high levels of stress and mental health issues; ${ }^{60}$ and the inaccessibility of the community and built environmentall of which are social determinants of health. ${ }^{61}$

Monitoring inequalities in health provision to different subgroups such as those of children with neurologic conditions is a strategy to indicate whether the right to health is being met, and provide guidance in areas that still need to be addressed. $^{62}$ Several health indicators have been set by established international parameters such as the UN SDGs. These indicators support improving coverage of health services, reducing risk factors in the environment (such as violence and physical exposures to chemicals and other potential harmful factors), and improving nutrition and services that facilitate and promote maternal health and child development, from early years and thourghout the life span. ${ }^{63}$

Research identifying existing barriers toward the enactment of rights exist, but has been poorly translated into services and policymaking, and has consequently adversely effected the lives of children with disabilities and their families. ${ }^{64,65}$ There is a critical role to be played by the professionals who serve these families in the health and education sectors to advocate for, and give voice to, children who may otherwise fall through the cracks. However, there is a paucity of information addressing effective strategies and identifying the potential effect of health care providers' advocacy efforts. This information is particularly scarce for children with neurological conditions. However, a few aspects related to the care of these populations are closely connected to rights-based approaches. The links between existing practices and potential areas of development in rights-based approaches will be outlined later.

\section{Looking to the Future: Rights- Based Approaches in Child Neurology}

\section{Life-Span Approach: Start Early, Document Well, Care Throughout}

Evidence supports that early investments in health are related to long-term sustained improvements in human and social capital; investment in early interventions for populations of children at risk can not only influence better development and health outcomes, but can also contribute to creating a rightsrespecting society with a social structure that continuously supports positive development. ${ }^{66}$ The life cost of treating neurologic conditions across the lifespan is tremendous, but can potentially be decreased through implementing or strengthening the use of evidence-based practices, and rightsbased approaches. ${ }^{67}$ In many communities, diagnosis and access to appropriate services for children who present with early developmental delays are not available, violating the right to health and appropriate care. Early detection, diagnosis, and referral to proper services is a public health challenge in many communities around the world. ${ }^{68}$

Investing in better early beginnings for children with conditions such as autism spectrum disorders and cerebral palsy $(\mathrm{CP})$ is one possible direction toward implementing rights-based approaches. Implementing this requires multilevel action, including: (1) implementing health policies that facilitate early screening and early intervention, (2) adopting systems-wide changes promoting prompt diagnosis and referral within health care and across systems of care (ie, health, education, and social services), (3) supporting community programs favoring cognitive, physical, and social development at the location where families and children live (ie, leisure, community engagement, youth participation in civil life, and decision-making). ${ }^{69}$

As children grow older, their dynamic ecology requires constant adaptations and re-assessments of ongoing needs to guarantee that they are provided equal opportunities in obtaining adequate care. School-age children may require integrated health and education systems that can support their needs, which includes providing adapted equipment, training education professionals involved in the alignment with health care and rehabilitation, and making any necessary adaptations to transportation, after school care, and the school's and community's built environment. $^{70,71}$ There is a need for health care providers to act beyond the clinic and act on changing the communities where their patients live. Partnering with 
grassroots organizations, providing knowledge and education about disabilities and engaging in constructive dialogs to create resources about disabilities with community groups and community-based services can foster the creation of social support networks that will contribute to better child development, strengthen families, and in consequence solidly support the right to health.

The UN SDGs also endorse specific health outcomes for people with disabilities and children, including the creation of policies that support their specific needs. Collecting disaggregate data on disabilities (by type of disability) is one of the measures recommended to contribute to the proper assessment of the current situation of children wih disabilities and their families, to develop goals and programmes based on real needs. ${ }^{72,73}$ Health care providers can inform public health agencies and decision-makers about the type of data that is most relevant to increase the accuracy of diagnosis and the creation of targeted interventions. One such example is the creation of patient registries that can raise the profile of given conditions such as CP. Population-based registries can contribute to improved surveillance, facilitate prevention efforts, foster key discoveries of intrinsic (ie, new genetic pathways) and extrinsic (ie, social and material deprivation) factors related to conditions. ${ }^{74,75}$ It can also raise public awareness about conditions, increasing the visibility of the needs of these populations, prompting its inclusion in public health campaigns, and informing service delivery and future research. $^{76}$

A rights-based approach to neurologic conditions also guarantees that children are cared for throughout their life span. Pediatric societies in different countries support a guided approach to transition of care from pediatric to adult systems, and stress the importance of following children with neurologic conditions and other complex care needs through this key transition period.

Ensuring that rights are respected implies considering the high prevalence concurrent of mental health issues and social problems that children with disabilities face as they grow older, and address matters such as sexuality, autonomy and self-management in the care of these youth as they transition to adulthood. ${ }^{77} \mathrm{~A}$ comprehensive approach will also consider access to rights as individuals with disabilities grow older, including creating and advocating for systems and societies where they can find employment that meets their vocational and self-care needs, and living arrangements that account for their autonomy while caring for complex health care needs. ${ }^{78}$ It is imperative to also advocate for societies that include insurance and other tax and financial benefits that are tailored to individual needs, and are not exclusively based on dependency from caregivers. ${ }^{79}$ Health care professionals are often part of teams that decide or support decisions that influence resources and services allocation for these clients. These interactions create unique opportunities to advocate for rights-based approaches and to generate discussions where the child and the family are given agency and autonomy to contribute to society and be fully integrated as equal members in all aspects.

\section{Promoting Participation: Making Children Actors of Their Own Story}

For children with disabilities, the "right to play" (Article 31 under the CRC and Article 30 under the CRPD) is as important as their right to education and health. Play is essential to live fulfilling lives and actively participate in their communities. Nevertheless, children with different neurologic conditions participate less in their communities than same-age peers without disabilities. ${ }^{80}$ The activities they partake in are more informal, often taking place at home and with their families, but less in community life and organized social leisure activities that are crucial for their development. ${ }^{81}$ The types of activities children can partake in are restricted in great part due to barriers in the environment, such as inaccessibility in the built environment, lack of training among staff involved in different activities, and unavailability of adequate information for families. ${ }^{82}$

A crucial feature of enacting human rights is agency and active participation in civil life. Children with neurologic conditions are often limited in their ability to actively participate in decision-making that directly affects them, including processes related to their health care and to citizenship building. As such, children should be able to express their views when decisions are being made about their care, in a balanced patient-centered and family-centered approach. When transitioning from pediatric to adult services, children and families should be informed about the service options available to them, and about policies that exist and may be relevant for their adult life (such as tax benefits, educational and vocational training, and housing and social welfare options). ${ }^{83}$

Health care providers can play a role in promoting the participation of children with disabilities by supporting interventions that promote participation in leisure and in the community, as well as including questions about their preferences for activities ${ }^{84}$ as part of "health check" visits; this can further be supported by informing children and their families about existing services and policies that can support these important endeavors, such as existing leisure activities, self-advocacy training and citizenship-building activities. ${ }^{85}$ Health professionals should also be responsible for creating awareness about disability in the community at large, and supporting families in understanding the importance of child autonomy and self-advocacy, whereas empowering families to also advocate effectively for their children's rights.

\section{Bringing Children, Families and Community to the Examination Table: Establishing and Advocating for the Right Priorities}

Different consensus studies have defined some priorities in health care that align with a rights perspective. Such priorities include generating awareness about disabilities, integration of community organizations and educational institutions in a holistic perspective of health and care, and shared decisionmaking among health care providers, children and families for children with neurologic conditions such as epilepsy ${ }^{86}$ and autism spectrum disorders. ${ }^{87}$ 
Health care providers should encourage and support families in assuming an active role in making decisions concerning the diverse aspects of their child's life. Important areas to support family and child autonomy includes education, rehabilitation and medical treatments, as well as living arrangements and employment. By supporting a shift from a medical model, in which service providers are seen as experts, to a family-centered model with the family playing an integral role in all steps of decisions and ongoing care, health care providers can contribute to implementing rights-based approaches. $^{88}$

Supporting child self-advocacy and family advocacy may include increasing awareness of existing community organizations, and parent support groups that can help families identify others with similar challenges and obtain the right information to make informed decisions. Examples exist that support positive outcomes when decision-making power is given to families, with the help of caring professionals to identify the best evidence-based treatments, point to the best options for care, and consider intervention options that encourage community participation and active citizenship. In fact, disability advocacy in this direction is critical to prevent adverse effects of discrimination, such as the lack of choices in treatment and care, inadequate school supports, and the frequent lack of accessibility in the community at large. ${ }^{89}$

Countries like Sweden, the UK and Australia have recently shifted their health care and social support provision systems to encourage family ownership in decision-making. ${ }^{90-92}$ These changes can be crucial in shifting the health care providers' role from holding the decision-making power, to being supporters of families' decisions, and into a rights-based approach to health care. ${ }^{93}$ Research in childhood disability is also gradually shifting from one that favors researchers' ownership and control to giving stakeholders the voice and power to identify the most important research questions. Through patient and family engagement strategic programs, health researchers are stimulated to do research with, rather than "on" families and children, and thus responding to direct family needs. ${ }^{94-96}$ Comparative effectiveness analysis of treatment options are also being done to support informed decisions, ${ }^{97}$ and propels advances in important, but often underexplored areas such as research in rare diseases, transition from pediatric to adult care, behavior management and mental health promotion strategies. ${ }^{98,99}$

\section{Bringing Rights to Practice: Social Justice Cases}

Several cases exist reporting on the violation of human rights for children with disabilities. In some cases, families or advocacy groups have taken legal action to guarantee that rights be respected-hat is, in the absence of rights-based approaches, litigation has become necessary to guarantee the protection of children with disabilities. Oftentimes, a false dichotomy is made between positive and negative rights, with negative rights merely demanding an absence of interference with the enjoyment of human rights (such as protection from discrimination based on disability status) and positive rights requiring affirmative investment in the promotion and realization of the rights of individuals with disabilities. This dichotomy is at the center of discussions on whether courts are predominately in favor of the more narrow and seemingly less costly negative-rights based approach in its examination of health care claims, as was evidenced in the case of Auton v. British Columbia. ${ }^{100}$ In this landmark case, a family accused the state, and won against it for not providing intensive behavior therapy for the preschool child who had autism. It is important to note that both positive and negative rights can be subject to human rights litigation; state parties (and service providers) are obligated to both put protections in place to ensure human rights are not infringed upon, as well as invest in programs, policies, and other initiatives to actively promote the rights of its citizens and service users.

Examples where rights were challenged include extreme landmark cases in which families challenged their right to terminate their severely disabled child's life ( $R$ v. Latimer), ${ }^{101}$ and cases where families challenged the education system for not accepting their child with CP into mainstream education, displacing them to special education without parental consent (Eaton v. Brant County Board of Education). ${ }^{102}$ Other cases (Eldridge v. British Columbia [A.G.]) concerned deaf parents who appealed against the government health care system's failure to provide medical interpretation services when caring for their child, a violation that found grounds in the Charter of Rights and Freedoms. ${ }^{103}$ In all of these cases, the common thread is that families needed to resort to legal action when the rights of their child were disrespected and no one else was acknowledging and acting on their claims. Health care providers could mitigate the need to appeal to legal action by planning services and care structures that account for these rights from design to implementation.

The strength of litigation resides on the potential whiplash effect it can cause, altering societal perceptions on disabilities, or dramatically changing the provision of care. For instance, in the IBA case, the perception of the claimants was that IBA could provide essential benefits for their child to be able to equally participate in society. The court decision was initially to not offer such interventions, as "emerging" therapies with limited evidence was not available for children without disabilities, therefore not constituting an inequity in terms of service offer. Nevertheless, the eventual final decision to provide this intervention has changed the course of interventions for autism in Canada. After one province decided to provide this service, other families and grassroots groups in other provinces decided to appeal and direct funds for this intervention, which became the standard of care in most provinces. Although important constraints in the allocation of services ought to be made to accommodate this new intervention, the litigation process caused more research to be done on the efficacy of this intervention. ${ }^{104,105}$

\section{Conclusion}

Many countries have predominately adopted a negative-rights based approach to the right to health, however, this is in direct contradiction with obligations under key international human 
rights treaties, such as the UDHR, the ICESCR, the CRPD and the CRC. ${ }^{106}$ A rights-based approach to health demands a holistic method that includes both an affirmative duty to actively promote as well as protect the rights of individuals, especially those that are members of particularly disadvantaged groups, such as children with neurologic conditions. For service providers, this entails not only the obligation to prohibit discrimination, but also the positive obligation to guarantee equality of opportunity in access to health goods and services. ${ }^{107}$ This positive obligation also demands service providers to act as advocates for their patients, as greater support in the full realization of the right to health can give rise to the enjoyment of other rights such as participation, social integration, employment, autonomy, and independence. ${ }^{108}$

A positive rights approach for children with disabilities and their families may support the creation of health services that respond to their needs, allocating resources to the most pressing issues indicated by children and families, valuing their priorities, and raising awareness about any violated rights for this population. The health care system as a whole can greatly contribute to promote accountability in rights promotion by facilitating the creation of spaces for discussion about resource-allocation according to families' and child's needs, developing health care policies that are informed by social justice and equality, and preventing the need for litigation. ${ }^{109}$

Health care providers are in a uniquely privilege position to drive change and promote the rights of populations who have been historically neglected and denied their rights. Conventions, treaties, policies, and tools exist to support these actions. A purposeful action toward practicing rights-based approaches and disseminating information about these, as well as raising awareness and advocating for the rights of children with disabilities, working in partnership with their families and children and youth themselves, can transform neurologic health care provision to a better, more humane care. Social justice and better societies can be the expected outcomes of such effort.

\section{Acknowledgments}

Work for this review was made possible through the Canada Research Chair (Canadian Institutes of Health Research) Program, the Kids Brain Health Network-a Network of Centers of Excellence Knowledge Translation grant, and infrastructure support from the Center in Interdisciplinary Research of the Greater Montreal (CRIR).

\section{References}

1. Shikako-Thomas K, Law M: Policies supporting participation in leisure activities for children and youth with disabilities in Canada: From policy to play. Disabil Soc 30:381-400, 2015

2. UNICEF: Convention on the Rights of the Child, 1989.

3. UN General Assembly, Convention on the Rights of Persons With Disabilities: Resolution/Adopted by the General Assembly, January 24, 2007, A/RES/61/106. Available at: http://www.refworld.org/docid/ 45f973632.html

4. UNICEF: Convention on the Rights of the Child, 1989

5. UN General Assembly, Convention on the Rights of Persons With Disabilities: Resolution/Adopted by the General Assembly, January 24,
2007, A/RES/61/106. Available at: http://www.refworld.org/docid/ 45f973632.html

6. UN General Assembly, Universal Declaration of Human Rights, December 10, 1948, 217A (III). Available at: http://www.refworld.org/docid/ 3ae6b3712c.html

7. Sabatello M: Children with disabilities: A critical appraisal. Int J Children Rights 21:464-487, 2013

8. What are Human Rights. Office of the United Nations High Commissioner for Human Rights 2017. http://www.ohchr.org/EN/Issues/Pages/ WhatareHumanRights.aspx

9. Ibid.

10. The International Bill of Human Rights includes the following: (1) The Universal Declaration of Human Rights (1948); (2) The International Covenant on Civil and Political Rights (1966); and (3) The International Covenant on Economic, Social, and Cultural Rights (1966)

11. Mégret F: The disabilities convention: Human rights of persons with disabilities or disability rights? Hum Rights Q 30:494-516, 2008

12. Monitoring Global Population Trends. The United Nations Department of Economic and Social Affairs: Population Division (UNPD) 2017. https://esa.un.org/unpd/wpp/

13. About the Convention on the Rights of the Child. UNICEF Canada, 2017. Available at: http://www.unicef.ca/en/policy-advocacy-for-chil dren/about-the-convention-on-the-rights-of-the-child.

14. Peterson-Badali M, Ruck M: Studying children's perspectives on selfdetermination and nurturance rights: Issues and challenges. J Soc Issues 64:749-769, 2008

15. Baumrind D: Reciprocal rights and responsibilities in parent-child relations. J Soc Issues 34:179-196, 1978

16. Rogers C, Wrightsman L: Attitudes toward children's rights: Nurturance or self-determination? J Soc Issues 34:59-68, 1978

17. Mauras M: Public policies and child rights: Entering the third decade of the convention on the rights of the child. Ann Am Acad Pol Soc Sci 633:52-65, 2010

18. United Nations Children's Fund (UNICEF): Celebrating 20 Years of the Convention on the Rights of the Child, The State of the World's Children, Special Edition. New York, NY: UNICEF, 2009

19. Daiute C: The rights of children, the rights of nations: Developmental theory and the politics of children's rights. J Soc Issues 64:701-723, 2008

20. CRIN: Child Rights International Network, 2017. Available at: http://See www.crin.org.

21. Daiute, 2008

22. Raman Shanti, et al: Human Rights And Child Health. J Paediatr Child Health 43:581-586, 2007. Web April 14, 2017

23. International Convention of the Rights of Persons with Disabilities and its Optional Protocol, U.N. GAOR, 61st Session, Item 67(b), U.N. Doc. A/61/611, December 6, 2006.

24. Mégret F: The disabilities convention: Human rights of persons with disabilities or disability rights? Hum Rights Q 30:494-516, 2008

25. Convention on the Rights of Persons with Disabilities: Why a Convention?. United Nations, 2017. Available at: http://www.un.org/disabil ities/convention/questions.shtml

26. Mackay D. Chairman of the CRPD Committee at the Time of Treaty Negotiation: Convention on the Rights of Persons with Disabilities: The Convention in Brief. United Nations, 2017. Available at: http://www.un. org/disabilities/convention/convention.shtml

27. Un.org. (2017). Article 8-Awareness-raisinglUnited Nations Enable. [online] Available at: https://www.un.org/development/desa/disabilities/ convention-on-the-rights-of-persons-with-disabilities/article-8-aware ness-raising.html (1) States Parties undertake to adopt immediate, effective and appropriate measures: (A) To raise awareness throughout society, including at the family level, regarding persons with disabilities, and to foster respect for the rights and dignity of persons with disabilities; (B) To combat stereotypes, prejudices and harmful practices relating to persons with disabilities, including those based on sex and age, in all areas of life; (C) To promote awareness of the capabilities and contributions of persons with disabilities.

28. Malhotra R: The disability rights movement: From charity to confrontation. Soc Democracy 26:132-135, 2012 
29. Sabatello M: Children with disabilities: A critical appraisal. Int J Children Rights 21:464-487, 2013

30. Goering S: Rethinking disability: The social model of disability and chronic disease. Curr Rev Musculoskelet Med 8:134-138, 2015

31. World Health Organization (WHO): What are Social Determinants of Health? 2017. http://www.who.int/social_determinants/sdh_definition/en/

32. Braveman P, Gottlieb L: The social determinants of health: It's time to consider the causes of the causes. Public Health Rep 129:19-31, 2014

33. UN General Assembly, Universal Declaration of Human Rights, December 10, 1948, 217 A (III). Available at: http://www.refworld.org/docid/ 3ae6b3712c.html

34. UN General Assembly, International Covenant on Economic, Social and Cultural Rights, December 16, 1966, United Nations, Treaty Series, vol. 993, p. 3. Available at: http://www.refworld.org/docid/3ae6b36c0.html.

35. Article 25 of the UDHR: "(1) Everyone has the right to a standard of living adequate for the health and well-being of himself and of his family, including food, clothing, housing and medical care and necessary social services, and the right to security in the event of unemployment, sickness, disability, widowhood, old age or other lack of livelihood in circumstances beyond his control. (2) Motherhood and childhood are entitled to special care and assistance. All children, whether born in or out of wedlock, shall enjoy the same social protection."

36. Article 12 of the ICESCR: "(1) The States Parties to the present Covenant recognize the right of everyone to the enjoyment of the highest attainable standard of physical and mental health. (2) The steps to be taken by the States Parties to the present Covenant to achieve the full realization of this right shall include those necessary for: (A) The provision for the reduction of the stillbirth-rate and of infant mortality and for the healthy development of the child; (B) The improvement of all aspects of environmental and industrial hygiene; (C) The prevention, treatment and control of epidemic, endemic, occupational and other diseases (D) The creation of conditions which would assure to all medical service and medical attention in the event of sickness."

37. The Right to Health is also included in the following human rights instruments: The International Convention on the Elimination of All Forms of Racial Discrimination (Article 5 (E) (iv); the Convention on the Elimination of All forms of Discrimination against Women (Articles 11 (1) (F), 12, and 14 (2) (B)); and the International Convention on the Protection of the Rights of All Migrant Workers and Members of Their Families (Articles 28, 43 (E) and 45 (C)). In fact, some of the Committees of these Conventions have also adopted general comments on the right to health.

38. OHCHR Factsheet 31. Office of the United Nations High Commissioner for Human Rights 2017. http://www.ohchr.org/Documents/Publica tions/Factsheet31.pdf

39. Sustainabledevelopment.un.org. (2017). Sustainable Development Goals: Sustainable Development Knowledge Platform. [online] Available at: https://sustainabledevelopment.un.org/?menu=1300 Accessed June 1, 2017.

40. Constitution of WHO: Principles. World Health Organization, http:// www.who.int/about/mission/en/

41. UN Committee on Economic, Social and Cultural Rights (CESCR), General Comment No. 14: The Right to the Highest Attainable Standard of Health (Art. 12 of the Covenant), August 11, 2000, E/C.12/2000/4. Available at: http://www.refworld.org/docid/4538838d0.html

42. Ibid., p. 3

43. A Human Rights-Based Approach to Health. UN Office of the High Commissioner for Human Rights 2017. http://www.ohchr.org/Docu ments/Issues/ESCR/Health/HRBA_HealthInformationSheet.pdf

44. OHCHR Factsheet 31. Office of the United Nations High Commissioner for Human Rights 2017. http:/www.ohchr.org/Documents/Publica tions/Factsheet31.pdf

45. Ibid.

46. "Equity demands that poorer households should not be disproportionately burdened with health expenses as compared to richer households" UN Committee on Economic, Social and Cultural Rights (CESCR), General Comment No. 14: The Right to the Highest Attainable Standard of Health (Article 12 of the Covenant), August 11, 2000, E/C.12/2000/4: 12(B).
47. UN Committee on Economic, Social and Cultural Rights (CESCR), General Comment No. 14: The Right to the Highest Attainable Standard of Health (Article 12 of the Covenant), August 11, 2000, E/C.12/2000/4: 12(b).

48. Such as being respectful of individuals', minorities', peoples and communities' culture, as well as respectful of gender and life-cycle requirements, while respecting confidentiality.

49. OHCHR Factsheet 31. Office of the United Nations High Commissioner for Human Rights, 2017. http://www.ohchr.org/Documents/Publica tions/Factsheet31.pdf, p.7

50. OHCHR Factsheet 31

51. Badia Marta, et al: Relationships Between Leisure Participation And Quality Of Life Of People With Developmental Disabilities. J Appl Res Intellect Disabil 2013. Web. April 14, 2017

52. Shikako-Thomas Keiko, et al: Picture me playing-A portrait of participation and enjoyment of leisure activities in adolescents with cerebral palsy. Res Dev Disabil 34:1001-1010, 2013. Web. April 14,2017

53. Raphael J, Colvin J: More than wheezing: incorporating social determinants into public policy to improve asthma outcomes in children. Pediatr Res 81:2-3, 2016

54. Sandel M, Wright R: When home is where the stress is: Expanding the dimensions of housing that influence asthma morbidity. Arch Dis Child 91:942-948, 2006

55. Wright R, Cohen R, Cohen S: The impact of stress on the development and expression of atopy. Curr Opin Allergy Clin Immunol 5:23-29, 2005

56. Oskoui Maryam, et al: Variation in cerebral palsy profile by socioeconomic status. Dev Med Child Neurol 58:160-166, 2015

57. Oskoui Maryam: Disentangling Racial And Ethnic Disparities In Cerebral Palsy. Dev Med Child Neurol 57:791-792, 2015

58. Myrill Solaski, Majnemer Annette, Oskoui Maryam: Contribution of socio-economic status on the prevalence of cerebral palsy: A systematic search and review. Dev Med Child Neurol 56: 1043-1051, 2014

59. Michael Shevell, Dagenais Lynn, Oskoui Maryam: The epidemiology of cerebral palsy: New perspectives from a Canadian Registry. Semin Pediatr Neurol 20:60-64, 2013

60. Raina P, O'Donnell M, Schwellnus $\mathrm{H}$, et al: Caregiving process and caregiver burden: Conceptual models to guide research and practice. BMC Pediatr 4:1, 2004. https://doi.org/10.1186/1471-2431-4-1

61. Shikako-Thomas K, Majnemer A, Colver A, et al: Look around me: Environmental context for adolescents with cerebral palsy (CP). Dev Med Child Neurol 55:84-86, 2013

62. Hosseinpoor A, Bergen N, Schlotheuber A: Promoting health equity: WHO health inequality monitoring at global and national levels. Glob Health Action 8:29034, 2015

63. Pedrana L, Pamponet M, Walker R, et al: Scoping review: National monitoring frameworks for social determinants of health and health equity. Glob Health Action 9:28831, 2016

64. Shikako-Thomas K, Law M: Policies supporting participation in leisure activities for children and youth with disabilities in Canada: From policy to play. Disabil Soc 30:381-400, 2015

65. Shepherd C, Waddell C: A qualitative study of autism policy in Canada: Seeking consensus on children's services. J Autism Dev Disord 45:3550-3564, 2015

66. Maitra C, Hodge A, Jimenez Soto E: A scoping review of cost benefit analysis in reproductive, maternal, newborn and child health: What we know and what are the gaps? Health Policy Plan 31:1530-1547, 2016

67. Knapp M, Romeo R, Beecham J: Economic cost of autism in the UK. Autism 13:317-336, 2009

68. Khan N, Gallo L, Arghir A, et al: Autism and the grand challenges in global mental health. Autism Res 5:156-159, 2012

69. Five Numbers to Remember About Early Childhood DevelopmentCenter on the Developing Child at Harvard University. Center on the Developing Child at Harvard University 2017. http://developingchild. harvard.edu/resources/five-numbers-to-remember-about-early-childhood-development/ 
70. Elsabbagh M, Yusuf A, Prasanna S, et al: Community engagement and knowledge translation: Progress and challenge in autism research Autism 18:771-781, 2014

71. Shah Seema: Canada's implementation of the right to education for students with disabilities. Int J Disabil Dev Educ 57:5-20, 2010

72. Infographic Disability: Inclusive SDGs. United Nations 2017. http:// www.un.org/disabilities/documents/sdgs/disability_inclusive_sdgs.pdf. Accessed February 17, 2017

73. Zwicker Jennifer, Zaresani Arezou, Emery JC Herb: Describing heterogeneity of unmet needs among adults with a developmental disability: An examination of the 2012 Canadian Survey on disability. Res Dev Disabil 65:1-11, 2017

74. Oskoui M, Gazzellone M, Thiruvahindrapuram B, et al: Clinically relevant copy number variations detected in cerebral palsy. Nat Commun 6:7949, 2015

75. Oskoui M, Messerlian C, Blair A, et al: Variation in cerebral palsy profile by socio-economic status. Dev Med Child Neurol 58:160-166, 2015

76. Hurley DS, Sukal-Moulton T, Gaebler-Spira D, et al: Systematic review of cerebral palsy registries/surveillance groups: Relationships between registry characteristics and knowledge dissemination. Int J Phys Med Rehabil 3:266, 2015. https://doi.org/10.4172/2329-9096.1000266

77. Kaufman M, Pinzon J: Transition to adult care for youth with special health care needs. Paediatric Child Health 12:785-793, 2007

78. American Academy of Pediatrics, American Academy of Family Physicians, and American College of Physicians-American Society of Internal Medicine: American Academy of Pediatrics, American Academy of Family Physicians, \& American College of Physicians-American Society of Internal Medicine. A consensus statement on health care transitions for young adults with special health care needs. Pediatrics 110:1304-1306, 2002

79. Frutos E, Castello J: Equal health, equal work? The role of disability benefits in employment after controlling for health status. Eur J Health Econ 16:329-340, 2014

80. Engel-Yeger B, Jarus T, Anaby D, et al: Differences in patterns of participation between youths with cerebral palsy and typically developing peers. Am J Occup Ther 63:96-104, 2009

81. Shikako-Thomas K, Kolehmainen N, Ketelaar M, et al: Promoting leisure participation as part of health and well-being in children and youth with cerebral palsy. J Child Neurol 29:1125-1133, 2014

82. Anaby D, Hand C, Bradley L, et al: The effect of the environment on participation of children and youth with disabilities: A scoping review. Disabil Rehabil 35:1589-1598, 2013

83. Hunt Paul, Mesquita Judith: Mental disabilities and the human right to the highest attainable standard of health. Hum Rights Q 28:332-356, 2006

84. Shikako-Thomas Keiko, et al: Are you doing what you want to do? Leisure preferences of adolescents with cerebral palsy. Dev Neurorehabil 18:234-240, 2013

85. Shikako-Thomas K, Law M: Policies supporting participation in leisure activities for children and youth with disabilities in Canada: From policy to play. Disabil Soc 30:381-400, 2015

86. Berg A, Baca C, Loddenkemper T, et al: Priorities in pediatric epilepsy research: Improving children's futures today. Neurology 81:1166-1175, 2013

87. Elsabbagh M, Yusuf A, Prasanna S, et al: Community engagement and knowledge translation: Progress and challenge in autism research. Autism 18:771-781, 2014

88. Darrah J, Magil-Evans J, Adkins R: How well are we doing? Families of adolescents or young adults with cerebral palsy share their perceptions of service delivery. Disabil Rehabil 24:542-549, 2002
89. Armstrong S: Disability advocacy in the Charter era: A symposium on disability and the law. J Law Equal 2:33-91, 2003

90. Mark Sherry: Welfare reform and disability policy in Australia [online]. Just Policy: A Journal of Australian Social Policy, No. 28:3-11, 2002. Availability: http://search.informit.com.au/documentSummary; dn=200301329;res=IELAPA\%20ISSN:\%201323-2266

91. "Our Health, Our Care, Our Say: A New Direction For Community Services". HM Government: Department of Health. N.p., 2017. Web. November 14, 2016. Availability: https://www.gov.uk/government/ uploads/system/uploads/attachment_data/file/272238/6737.pdf

92. “Sweden's Disability Policy”. sweden.se. N.p., 2017. Web. November, 14 2016. Available at: https://sweden.se/society/swedens-disability-policy/

93. Allmark P, Machaczek K: Financial capability, health and disability. BMC Public Health 15, 2015

94. Armstrong M, Morris C, Abraham C, et al: Interventions utilising contact with people with disabilities to improve children's attitudes towards disability: A systematic review and meta-analysis. Disabil Health J 10:11-22, 2017

95. Morris C, Blake S, Stimson A, et al: Resources for parents raising a disabled child in the UK. Paediatr Child Health 26:406-408, 2016

96. Robinson D: PenCRU childhood disability research. Peninsula Cerebra Research Unit 2017. http://www.pencru.org/projectsmeetings/publica tions/\#Tjpd00x6GbGuQYCj.99

97. Forsythe L, Frank L, Workman T, et al: Patient, caregiver and clinician views on engagement in comparative effectiveness research. J Comp Eff Res 2017

98. Morris C, Janssens A, Shilling V, et al: Meaningful health outcomes for paediatric neurodisability: Stakeholder prioritisation and appropriateness of patient reported outcome measures. Health Qual Life Outcomes $13: 406-408,2015$

99. Morris C, Simkiss D, Busk M, et al: Setting research priorities to improve the health of children and young people with neurodisability: a British Academy of Childhood Disability-James Lind Alliance Research Priority Setting Partnership e006233. BMJ Open 5 2015. e006233

100. Jackman Martha: Charter review as a health care accountability mechanism in Canada. Health Law J 18:1-29, 2010

101. Enns Ruth: A Voice Unheard: The Latimer Case and People With Disabilities. Halifax, NS: Fernwood Pub, 1999

102. Keene J: Discrimination in the Provision of Government Services and S.15 of the Charter: Making the best of the judgements in Egan, Thibaudeau, and Miron. J Law Soc Policy 11:107-164, 1995

103. Jackman Martha: Charter review as a health care accountability mechanism in Canada. Health Law J 18:1-29, 2010

104. Chisholm R: Not a Leg to Stand On: The Unconstitutionality of New Brunswick Regulation 84-20, Section 2(d). Windsor Yearbook of Access to Justice 24:77-110, 2017

105. Hodes C: Dignity and the conditions of truth: What equality needs from law. Can J Women Law 19:273-304, 2007

106. Jackman Martha: Charter review as a health care accountability mechanism in Canada. Health Law J 18:1-29, 2010

107. Hunt Paul, Mesquita Judith: Mental disabilities and the human right to the highest attainable standard of health. Hum Rights Q 28:332-356, 2006

108. Ibid, Hunt Paul, Mesquita Judith: Mental disabilities and the human right to the highest attainable standard of health. Hum Rights $Q$ 28:332-356, 2006

109. Jackman Martha: Charter review as a health care accountability mechanism in Canada. Health Law J 18:1-29, 2010 